\title{
Determination of a new constant to estimate glomerular filtration rate in pediatrics
}

\author{
Melina Porporato, M.D. ${ }^{a}$, Elsa Isern, M.D. ${ }^{a}$, Mariana Pellegrini, M.D. ${ }^{a}$, \\ Paula Carlopio, M.D. ${ }^{a}$, Jorgelina M. Becchio, M.D. ${ }^{a}$, Mariela Ríos, M.D. ${ }^{a}$, \\ María B. Irigoyen, M.D. ${ }^{a}$, Fabiana Vonmaro, Biochemist ${ }^{b}$ and Diana Massó, M.D. ${ }^{a}$
}

\begin{abstract}
Introduction. In pediatrics, glomerular filtration rate (GFR) may be estimated by measured corrected creatinine clearance $(\mathrm{mcCrCl})$ $\left(\mathrm{mL} / \mathrm{min} / 1.73 \mathrm{~m}^{2}\right)$ or the Schwartz formula $(\mathrm{eGFR}=$ height $/$ plasma creatinine $\mathrm{x} k$ ). The constant $k$ depends on the plasma creatinine determination method: $k=0.55$ for the Jaffe colorimetric method and $k=0.413$ for the enzymatic method. Our laboratory uses the compensated kinetic colorimetric assay (CKC), and differences are observed between the estimated and measured GFR.

Hypothesis: The proposed values of $k$ do not adjust to the CKC method for plasma creatinine. Objective. To calculate a $k$ value that allows to estimate GFR through creatinine measurement with CKC.

Methods. Correlational, descriptive design. Patients aged 3-18 years seen at the Division of Pediatric Nephrology between July 2017 and January 2018 with normal or altered GFR, bladder and bowel control, and signed consent were included. Malnourished and myelomeningocele patients were excluded. Studied variables were plasma and urine creatinine, height, and 24-hour urine output.
\end{abstract}

Results. A total of 184 patients were analyzed, their mean age was 10 years. Median $\mathrm{mcCrCl}$ was $123 \mathrm{~mL} / \mathrm{min} / 1.73 \mathrm{~m}^{2}$. The linear correlation between height and plasma creatinine and $\mathrm{mcCrCl}$ resulted in a $k$ value of $0.499(\mathrm{r}=0.974$ and $\mathrm{r}^{2}=0.949$ ). The linear correlation between the estimated GFR $(k=0.499)$ and $\mathrm{mcCrCl}$ resulted in a 0.999 B coefficient $\left(r=0.951\right.$ and $\left.\mathrm{r}^{2}=0.903\right)$. Conclusion. According to this study, the constant that allows to estimate GFR when measuring plasma creatinine with the CKC method is 0.499 . Key words: glomerular filtration rate, colorimetric assay, creatinine.

http:/ / dx.doi.org/10.5546/ aap.2021.eng.e428

To cite: Porporato M, Isern E, Pellegrini M, Carlopio P, et al. Determination of a new constant to estimate glomerular filtration rate in pediatrics. Arch Argent Pediatr 2021;119(5):e428-e434.

\author{
Acronyms and abbreviations \\ CKC: Compensated kinetic \\ colorimetric assay. \\ eGFR: Estimated glomerular \\ filtration rate. \\ EM: Enzymatic method. \\ GFR: Glomerular filtration rate. \\ IDMS: Isotope dilution mass \\ spectrometry method. \\ JCM: Jaffe colorimetric method. \\ mcCrCl: Measured corrected \\ creatinine clearance. \\ PCr: Plasma creatinine.
}

\section{INTRODUCTION}

The measurement of kidney function, both in adults and children, underwent several changes since the development of the Kidney Disease Outcomes Quality Initiative (K/ DOQI) guidelines in $2002^{1}$ and their subsequent update, Kidney Disease: Improving Global Outcomes (KDIGO), in 2012. ${ }^{2}$

These guidelines, in addition to reaching a consensus on the definition, evaluation, and classification of stages of chronic kidney disease (CKD), recommend assessing kidney function not only through plasma creatinine $(\mathrm{PCr})$ determination but also through glomerular filtration rate (GFR). The latter may be performed by measuring the clearance $(\mathrm{Cl})$ of endogenous substances (such as creatinine) or exogenous ones (such as inulin, iothalamate or iohexol) or may be estimated through predefined formulas. ${ }^{3}$ Despite being specific, exogenous markers are not routinely used in clinical pediatrics given their complex measurement. For this reason, GFR in pediatrics may be estimated with the well-known formula of measured creatinine 
clearance corrected $(\mathrm{mcCrCl})$ for $1.73 \mathrm{~m}^{2}$ of body surface area with a 24-hour urine sample ${ }^{4}$ or with the formula developed by Schwartz in $1976,{ }^{5}$ known as estimated glomerular filtration rate (eGFR), which allows to calculate GFR using plasma creatinine and patient height:

eGFR $=$ height $(\mathrm{cm}) \times k / \mathrm{PCr}(\mathrm{mg} / \mathrm{dL})$

By using a linear correlation between the height and creatinine values versus $\mathrm{mcCrCl}$, Schwartz obtained an initial constant $k$ of 0.55 .

This constant allows to correct methodological errors and is intrinsically related to the measurement method used for creatinine. The formula was developed using the Jaffe colorimetric method (JCM). ${ }^{6}$ In this formula, in order to measure plasma creatinine, an orange-colored reaction that occurs when creatinine combines with picrate is used. This reaction is non-specific because there are positive and negative interferences with other chromogens which result in an overestimation or underestimation of creatinine.

Later on, some laboratories started measuring plasma creatinine using an enzymatic method (EM), which is more specific and accurate, and is not subject to marked interferences with other substances. ${ }^{7}$ A new correlation was performed with this method in 2009 (called bedside) through which the $k$ value was determined at $0.413 .{ }^{8}$

Nowadays, in several health care facilities, including our hospital, creatinine levels are determined using a third method, known as compensated kinetic colorimetric assay (CKC), also called the Jaffe kinetic method, which minimizes the interferences of the JCM. ${ }^{9}$

Unfortunately, there are few studies in the bibliography regarding the value of $k$ suggested to estimate GFR with the CKC. ${ }^{10-13}$ In short, there are 3 methods to measure plasma creatinine, which should use different $k$ values to estimate GFR based on the Schwartz formula. For the JCM, since 1976, a $k$ value of 0.55 has been used; ${ }^{5}$ for the EM, since 2009, a $k$ value of 0.413 has been used; ${ }^{8}$ however, for the CKC there is no strong suggestion regarding the adequate $k$ value. ${ }^{11}$

Since 2010, our facility has been using the CKC. In routine practice, there is an overestimation of the eGFR when using a $k$ value of 0.55 and an underestimation when using a value of 0.413 ( $\mathrm{mcCrCl}$ is considered to be the gold standard).

\section{OBJECTIVES}

- To investigate which is the adequate $k$ value for the measurement method used in our laboratory (CKC) in patients younger than 18 years, validating the pre-existing mathematical model proposed by Schwartz in 1976.

- To assess the correlation between eGFR and $\mathrm{mcCrCl}$ using the new $k$ value obtained.

\section{MATERIALS AND METHODS}

This was a descriptive and correlational study conducted between July $1^{\text {st }}, 2017$ and January $30^{\text {th }}$, 2018. The initial hypothesis was that none of the $k$ values proposed to date allows to estimate the GFR more accurately when plasma creatinine is measured through CKC.

Patients aged 3-18 years with normal GFR or any stage of chronic kidney disease (CKD), with bladder and bowel control, seen at the Division of Nephrology of the Department of Pediatrics of Hospital Nacional Profesor A. Posadas were included in the study.

Malnourished patients according to the guidelines of the Sociedad Argentina de Pediatría ${ }^{14}$ and patients diagnosed with myelomeningocele were excluded.

Participants who did not undergo all requested lab tests or did not have an adequate 24-hour urine sample collection were left out. In order to determine if urine collection was adequate, the measurement of daily urinary creatinine excretion per kilogram of body weight ( $\mathrm{UCr} / \mathrm{kg} /$ day) was used taking as reference values those between the $5^{\text {th }}$ and $95^{\text {th }}$ percentiles according to age and sex. ${ }^{15}$

The following variables were analyzed: sex, weight, height, plasma creatinine, and $\mathrm{mcCrCl}$ (expressed as $\mathrm{mL} / \mathrm{min} / 1.73 \mathrm{~m}^{2}$ ). Plasma creatinine was measured using the Jaffe modified method (CKC) and processed in a Cobas $6000 \mathrm{C} 501{ }^{\circledR}$ autoanalyzer (Roche, Basel); this test has been standardized against the reference isotope dilution mass spectrometry method (IDMS). The other variables necessary to estimate $\mathrm{mcCrCl}$ based on the formula described above $^{4}$ were urinary creatinine, measured as per the Jaffe kinetic method, and total urinary output, corrected for $1.73 \mathrm{~m}^{2}$ of body surface. Body surface area was determined using the DuBois formula. ${ }^{16}$

This study was approved by the Clinical Research Ethics Committee of our facility. All included patients signed the informed consent or assent, as applicable.

The SPSS ${ }^{\circledast}$ statistical package, version 22.0, and the XLSTAT $2018.2^{\circledR}$ complement were used for the statistical analysis. 
Given the multivariate model with 9 regressor variables, a minimum of 90 patients were included in the protocol. Continuous variables were expressed as mean or median based on their distribution, with their corresponding standard deviation (SD) or interquartile range (IQR). Categorical variables were described as absolute or relative values (percentage).

Two linear regression models were developed:

- First model: height/PCr and $\mathrm{mcCrCl}$ for $1.73 \mathrm{~m}^{2}$ of body surface area. ${ }^{5}$

- Second model: GFR estimated by formula (with the new $k$ value obtained) and $\mathrm{mcCrCl}$ for $1.73 \mathrm{~m}^{2}$. Once correlations were established, Pearson's correlation coefficient $(r)$ and the coefficient of determination $\left(\mathrm{r}^{2}\right)$ were estimated.

\section{RESULTS}

In the study period, 242 patients were included; of these, $58(31 \%)$ were excluded: 38 for having pending lab results and 20 due to

TABLE 1. Characteristics of the studied population $(n=184)$

\begin{tabular}{lc}
\hline Variables & Data \\
\hline Number of patients & 184 \\
Age (years): M (IQR) & $10.5(5.8)$ \\
Boys: $\mathrm{n}(\%)$ & $92(50)$ \\
Weight $(\mathrm{kg}): \mathrm{M}(\mathrm{IQR})$ & $35.7(24)$ \\
Height $(\mathrm{cm}): \mathrm{M}(\mathrm{IQR})$ & $139(34)$ \\
$\mathrm{BSA}\left(\mathrm{m}^{2}\right): \mathrm{M}(\mathrm{IQR})$ & $1.2(0.6)$ \\
$\mathrm{PCr}(\mathrm{mg} / \mathrm{dL}): \mathrm{M}(\mathrm{IQR})$ & $0.5(0.2)$ \\
$\mathrm{mcCrCl}\left(\mathrm{mL} / \mathrm{min} / 1.73 \mathrm{~m}^{2}\right): \mathrm{X}(\mathrm{SD})$ & $123(46.3)$ \\
\hline
\end{tabular}

M: median, IQR: interquartile range, n: number, $\mathrm{X}$ : mean, SD: standard deviation, BSA: body surface area, PCr: plasma creatinine, $\mathrm{mcCrCl}$ : measured corrected creatinine clearance $\left(\mathrm{mL} / \mathrm{min} / 1.73 \mathrm{~m}^{2}\right)$. an inadequate 24-hour urine sample collection. Out of the 184 studied patients (Table 1), $92(50 \%)$ were males and 23 were older than 13 years.

The median age was 10.5 years (range: 3.2-18) with an abnormal distribution. The most common diagnoses among studied patients were uropathy and dysplasia (33.5\%) (Table 2).

Regarding studied variables related to kidney function, the median plasma creatinine value was $0.5 \mathrm{mg} / \mathrm{dL}$, and the $\mathrm{mcCrCl}$ showed a normal distribution (Figure 1), with a mean value of $123 \mathrm{~mL} / \mathrm{min} / 1.73 \mathrm{~m}^{2}$ (SD: $46.3 \mathrm{~mL} / \mathrm{min} / 1.73 \mathrm{~m}^{2}$ ). In addition, it was observed that $57 \%$ of patients $(105 / 184)$ had a $\mathrm{mcCrCl}$ higher than $90 \mathrm{~mL} /$ $\mathrm{min} / 1.73 \mathrm{~m}^{2}$ (Table 2).

\section{First model: Correlation between $\mathrm{mcCrCl}$ and the height/plasma creatinine ratio}

In order to assess the correlation between $\mathrm{mcCrCl}$ and the height/plasma creatinine ratio, a univariate linear regression model (first model) through the origin (without an intercept term) was developed. $\mathrm{mcCrCl}$ was considered the dependent variable or response and the height/ plasma creatinine ratio, the independent o regressor variable.

An unstandardized $\beta$ coefficient (constant $k$ ) of 0.499 was obtained; with a $95 \%$ confidence interval (CI) ranging from 0.482 to 0.515 . This regression presents a Pearson's correlation coefficient ( $\mathrm{r}$ ) of 0.974 and $\mathrm{a}^{2}=0.949$, showing the direct relation between studied variables (Figure 2).

\section{Second model: Correlation between $\mathrm{mcCrCl}$ and eGFR with the new $k$ value}

In order to assess the correlation between mcCrCl and eGFR using the new $k$ value $(0.499 \times$ height/ plasma creatinine $)$ proposed, a

TABLE 2. Classification of included patients

\begin{tabular}{|c|c|c|c|}
\hline \multicolumn{2}{|c|}{ By diagnosis } & \multicolumn{2}{|c|}{$\begin{array}{l}\text { By chronic kidney disease stage } \\
\text { by } \mathrm{mcCrCl}\left(\mathrm{mL} / \mathrm{min} / 1.73 \mathrm{~m}^{2}\right)\end{array}$} \\
\hline Diagnoses & $\mathbf{N}(\%)$ & Stage $^{*}$ & $\mathbf{N}(\%)$ \\
\hline $\begin{array}{l}\text { Uropathy and dysplasia } \\
\text { Glomerulopathies } \\
\text { Solitary kidney } \\
\text { Hematuria } \\
\text { Hemolytic uremic syndrome } \\
\text { Arterial hypertension } \\
\text { Lithiasis } \\
\text { Urinary tract infection } \\
\text { Other }\end{array}$ & $\begin{array}{l}62(33.5) \\
31(17) \\
23(12.5) \\
14(7.5) \\
12(6.5) \\
7(4) \\
6(3) \\
4(2) \\
25(14)\end{array}$ & $\begin{array}{c}\text { S1 }(\geq 90) \\
\text { S2 }(60-89) \\
\text { S3 }(30-59) \\
\text { S4 }(15-29) \\
\text { S5 }(<15)\end{array}$ & $\begin{array}{c}149(81) \\
17(9.23) \\
10(5.43) \\
8(4.34) \\
0(0)\end{array}$ \\
\hline
\end{tabular}

mcCrCl: measured corrected creatinine clearance. 
univariate regression model through the origin was developed. mcCrCl was considered the dependent variable or response and eGFR, the independent o regressor variable (Figure 3).
In this case, the $\beta$ coefficient was 0.999 (95\% CI: 0.965-1.033). A direct relation was again demonstrated between the dependent variable and the independent variable $(r=0.974$ and $\left.r^{2}=0.949\right)$.

\section{FIGURE 1. Histogram of distribution of measured corrected creatinine clearance $\left(\mathrm{mL} / \mathrm{min} / 1.73 \mathrm{~m}^{2}\right)$}

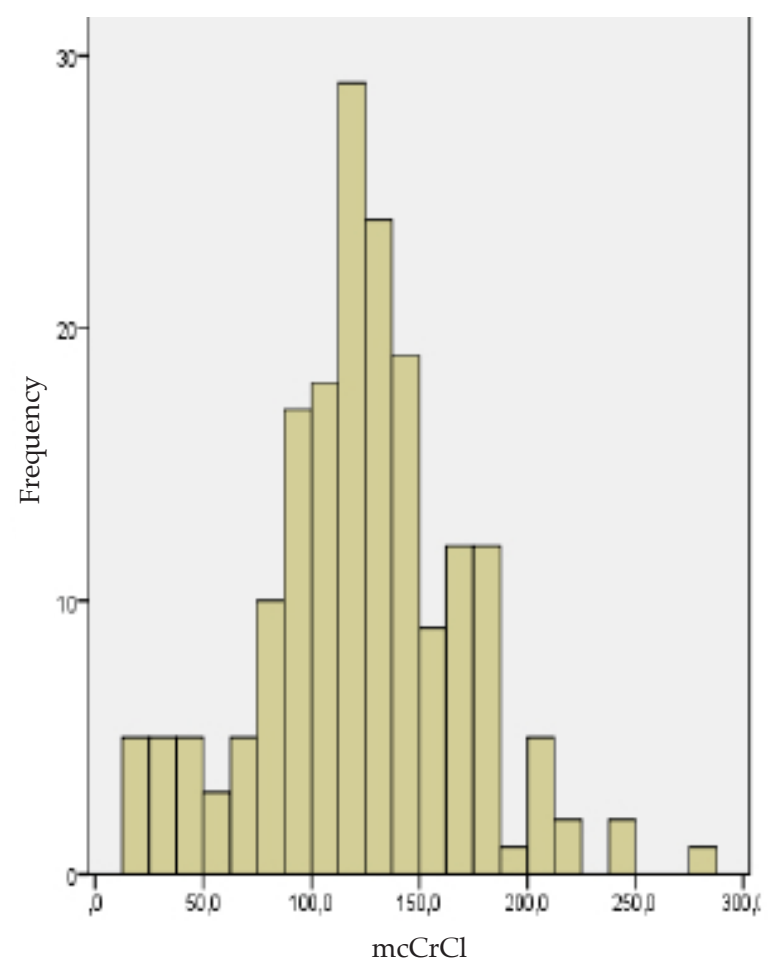

The mean $\mathrm{mcCrCl}$ is $123 \mathrm{~mL} / \mathrm{min} / 1.73 \mathrm{~m}^{2}(\mathrm{n}=184)$.

Standard deviation: $46.3 \mathrm{~mL} / \mathrm{min} / 1.73 \mathrm{~m}^{2}$. $\mathrm{mcCrCl}$ : measured corrected creatinine clearance $\left(\mathrm{mL} / \mathrm{min} / 1.73 \mathrm{~m}^{2}\right)$.

FIGURE 2. Linear correlation between height $(\mathrm{cm}) /$ plasma creatinine $(\mathrm{mg} / \mathrm{dL})$ and measured corrected creatinine clearance $\left(\mathrm{mL} / \mathrm{min} / 1.73 \mathrm{~m}^{2}\right)$

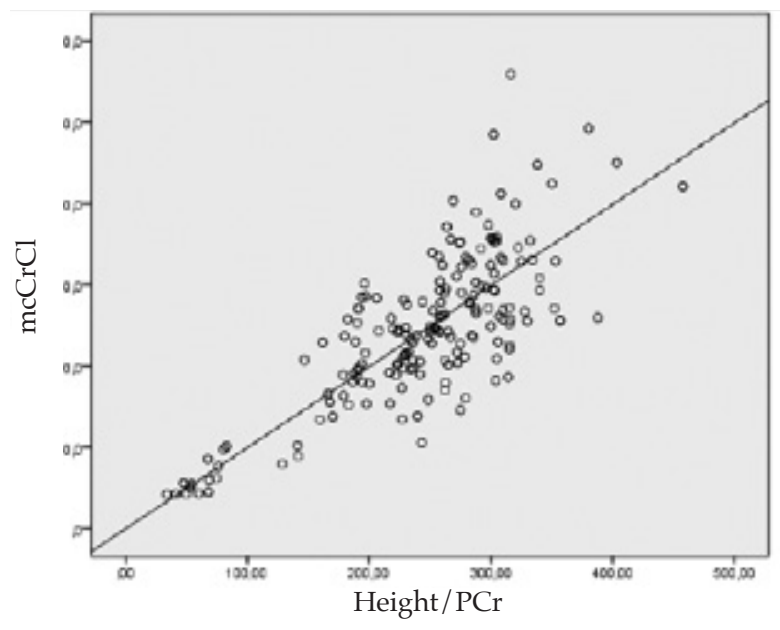

$\beta$ coefficient of 0.499 with $\mathrm{r}=0.974$ and $\mathrm{r} 2=0.949(\mathrm{n}=184)$.

PCr: plasma creatinine, $\mathrm{mcCrCl}$ : measured corrected creatinine clearance $\left(\mathrm{mL} / \mathrm{min} / 1.73 \mathrm{~m}^{2}\right)$. 


\section{Comparison between the median values of $\mathrm{mcCrCl}$ and eGFR using the new $k$ value}

If the median eGFR $\left(129 \mathrm{~mL} / \mathrm{min} / 1.73 \mathrm{~m}^{2}\right)$ using the constant found for the CKC is compared to the median $\mathrm{mcCrCl}\left(123 \mathrm{~mL} / \mathrm{min} / 1.73 \mathrm{~m}^{2}\right)$ (Figure 4), an eGFR overestimation of $5.8 \mathrm{~mL} /$ $\min / 1.73 \mathrm{~m}^{2}$ is observed.

\section{Comparison between median eGFR estimates using the different $k$ values}

If the two values of the constant $k$ previously suggested by Schwartz ${ }^{5,8}$ were used in the formulas to estimate GFR in our group of patients, the following would be observed: an overestimation of $13.2 \mathrm{~mL} / \mathrm{min} / 1.73 \mathrm{~m}^{2}$ with the

FIGURE 3. Linear correlation between the estimated glomerular filtration rate (with a $k$ value of 0.499) and the measured corrected creatinine clearance

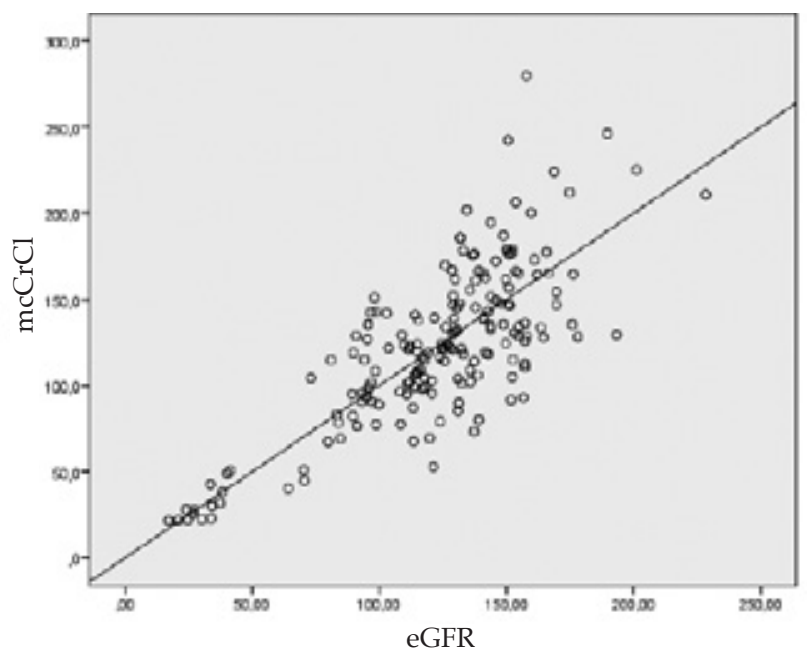

$\beta$ coefficient of 0.999 with $r=0.974$ and $r 2=0.949(n=184)$.

eGFR: estimated glomerular filtration rate, $\mathrm{mcCrCl}$ : measured corrected creatinine clearance $\left(\mathrm{mL} / \mathrm{min} / 1.73 \mathrm{~m}^{2}\right)$.

FIGURE 4. Box plot: Comparison between the median values of the estimated glomerular filtration rate (with a $k$ value of 0.499) and the measured corrected creatinine clearance

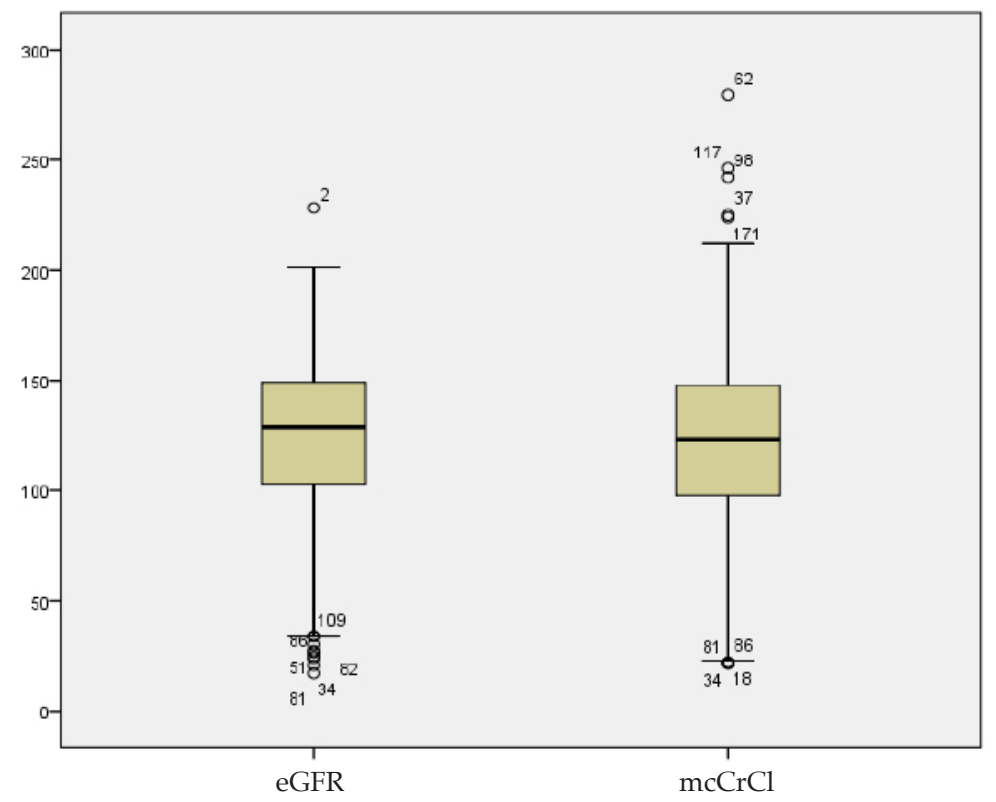

Median values of eGFR and $\mathrm{mcCrCl}$ of 128.9 and $123 \mathrm{~mL} / \mathrm{min} / 1.73 \mathrm{~m}^{2}$, respectively.

eGFR: estimated glomerular filtration rate, $\mathrm{mcCrCl}$ : measured corrected creatinine clearance $\left(\mathrm{mL} / \mathrm{min} / 1.73 \mathrm{~m}^{2}\right)$. 
$k$ value of 0.55 (JCM) and an underestimation of $22.22 \mathrm{~mL} / \mathrm{min} / 1.73 \mathrm{~m}^{2}$ with the $k$ value of 0.413 .

\section{DISCUSSION}

Pediatricians and pediatric nephrologists have always calculated eGFR based on height. However, after modifying the measurement method for plasma creatinine, we observed a wide variability of eGFR levels depending on whether the $k$ value adjusted to the JCM or the EM is used. These differences could affect the correct and rapid decision-making on treatment based on the eGFR level, for instance, to adjust the dose of medication in a patient with acute kidney injury.

The determination of serum creatinine is based on the Jaffe reaction, whose advantages include its simple analysis and low cost, but its main problem is the lack of specificity with interferences, both positive and negative. In order to minimize interferences, the CKC has 3 modifications: a) it performs a kineticcolorimetric reading, b) it performs a sample blank (to reduce the negative interference of bilirubin), and c) it introduces a negative correction factor of $-0.3 \mathrm{mg} / \mathrm{dL}$ (to minimize the positive interference of pseudochromogens, such as proteins, glucose, ascorbic acid, ketoacids, uric acid, among others). This compensation assumes that the interference is constant in all samples and that it may be excessive in patients with a low creatinine production rate and the variable presence of pseudochromogens, as is the case in the pediatric population. ${ }^{17}$

The CKC method used has been standardized against the IDMS method. Standardization is a method that allows to reduce differences between creatinine values obtained through different methods and their impact on the GFR results obtained through an equation.

In pediatrics, the most commonly used equation since 1976 has been that proposed by Schwartz, which uses plasma creatinine, patient height, and a constant $(k)$; the selection of the latter depends on the method used to measure creatinine and the study population.

For non-IDMS-traceable Jaffe methods, a $k$ value of 0.55 is used, and for IDMS-traceable $\mathrm{EM}$, a $k$ value of $0.413 .^{17}$

Schwartz conducted several studies; in 1976 he assessed 186 patients with plasma creatinine measurement through JCM and GFR ranging between 10 and $140 \mathrm{~mL} / \mathrm{min} / 1.73 \mathrm{~m}^{2}$, and found no differences between sexes nor between prepubertal and postpubertal patients using the same $k$ value. ${ }^{5}$ In a subsequent study, the same author determined different constants according to age and sex; he defined a $k$ value of 0.7 and 0.55 for adolescent boys and girls, respectively. ${ }^{18}$ In 2009, ${ }^{8}$ Schwartz modified the constant $(k=0.413)$ due to the change in the method used to measure creatinine $(\mathrm{EM})$ and included patients with $\mathrm{mcCrCl}$ ranging from 15 to $75 \mathrm{~mL} / \mathrm{min} / 1.73 \mathrm{~m}^{2}$. In 2016, there was a proposal to modify that formula based on normalized serum creatinine using a coefficient $(Q)$ obtained from the median plasma creatinine from a healthy population for age and sex using the enzymatic method, which is why it does not apply to our population nor to our measurement method for plasma creatinine. ${ }^{19} \mathrm{In}$ 2019 , the adequate formula to calculate eGFR in adolescent and young adults ${ }^{8}$ proposed by the KDIGO guidelines was questioned..$^{20,21}$

Our study was conducted in a population with a wider range of kidney function than that of patients initially studied by Schwartz; ${ }^{5}$ in addition, more than half of our patients $(57 \%)$ had a $\mathrm{mcCrCl}$ within reference values, with a small proportion of children $(18 \%)$ with advanced CKD $\left(<60 \mathrm{~mL} / \mathrm{min} / 1.73 \mathrm{~m}^{2}\right)$.

Afterwards, few studies have analyzed the correlation between eGFR and $\mathrm{mcCrCl}$ with CKC. ${ }^{10-13}$

In 2012, Hari also used CKC to measure plasma creatinine. The patients included in that study had a lower median $\mathrm{mcCrCl}$ than that of our participants ( 85.5 versus $123 \mathrm{~mL}$ / $\left.\min / 1.73 \mathrm{~m}^{2}\right)$; in addition, those authors found a different $k$ value $(0.42$ versus 0.499$)$ and a lower $\mathrm{r}^{2}$ (0.61 versus 0.949$)$ compared to our findings. ${ }^{11}$

A 2014 consensus proposes that the $k$ value should be adapted locally due to the great variation among laboratories in relation to the method used for creatinine determination. ${ }^{3}$ In agreement with this, we suggest using a $k$ value of 0.499 when plasma creatinine is measured with CKC.

When estimating the GFR using this new $k$ value, we tried to assess it in different study subgroups, and we noticed an underestimation in boys older than 13 years and an overestimation in patients with advanced CKD in relation to $\mathrm{mcCrCl}$. Therefore, we believe that, given the characteristics of the studied population, in the future we should plan a new study including a higher number of adolescent patients with $\mathrm{mcCrCl}<60 \mathrm{~mL} / \mathrm{min} / 1.73 \mathrm{~m}^{2}$, so as to draw more appropriate conclusions regarding these subgroups. 
When comparing eGFR with mcCrCl with a $k$ value of 0.499 , we observed a slight eGFR overestimation of $5.8 \mathrm{~mL} / \mathrm{min} / 1.73 \mathrm{~m}^{2}$.

One of the limitations of this study is that we used $\mathrm{mcCrCl}$ as the gold standard of GFR, knowing that it overestimates the real value of kidney function by $10-20 \%$ as a consequence of tubular creatinine secretion, which is even higher in pediatric patients with a drop in GFR. ${ }^{1}$

In relation to the statistical method used, despite the excellent correlation observed between the related and studied variables, we face the same difficulties as the original studies by Schwartz and his group: the analyzed variables do not show normality or homoscedasticity in their distribution. For this reason, conclusions drawn from this correlation should be assessed in the clinical setting, given that they lack the specificity typical of a pure linear correlation.

\section{CONCLUSION}

According to this study, the constant that allows to estimate GFR when measuring plasma creatinine with the CKC method is 0.499 .

\section{REFERENCES}

1. National kidney foundation. K/DOQI clinical practice guidelines for chronic kidney disease: evaluation, classification, and stratification. Am J Kidney Dis. 2002;39(2 Suppl 1):S1-266.

2. Kidney Disease: Improving Global Outcomes (KDIGO) CKD Work Group. KDIGO Clinical Practice Guideline for the Evaluation and Management of Chronic Kidney Disease. Kidney Int Suppl. 2012; 3:1-150.

3. Montañés Bermúdez R, Gràcia García S, Fraga Rodríguez GM, et al. Documento de consenso: recomendaciones sobre la utilización de ecuaciones para la estimación del filtrado glomerular en niños. An Pediatr (Barc). 2014; 80(5):326.e1-13.

4. Arant BS Jr. Edelmann CM Jr, Spitzer A. The congruence of creatinine and inulin clearances in children: use of the Technicon AutoAnalyzer. J Pediatr. 1972; 81(3):559-61.

5. Schwartz GJ, Haycock GB, Edelmann CM Jr, Spitzer A. A simple estimate of glomerular filtration rate in children derived from body length and plasma creatinine. Pediatrics. 1976; 58(2):259-63.

6. Jaffe M. Ueber den Niederschlag, welchen Pikrinsaure im normalen Harn erzeugt, und uber eine neue Reaction des Kreatinins. Zeitschrift für Physiologische Chemie.1886; 10(5):391-400.

7. Moss GA, Bondar RJ, Buzzelli DM. Kinetic enzymatic method for determining serum creatinine. Clin Chem.1975; 21(10):1422-6.

8. Schwartz GJ, Muñoz A, Schneider MF, Mak RH, et al. New equations to estimate GFR in children with CKD. J Am Soc Nephrol. 2009; 20(3):629-37.

9. Peake M. Whiting M. Measurement of serum creatininecurrent status and future goals. Clin Biochem Rev. 2006; 27(4):173-84.

10. Peduzzi P, Concato J, Kemper E, Holford TR, et al. A simulation study of the number of events per variable in logistic regression analysis. J Clin Epidemiol. 1996; 49(12):1373-9.

11. Hari P, Biswas B, Pandey R, Kalaivani M, et al. Updated height- and creatinine-based equation and its validation for estimation of glomerular filtration rate in children from developing countries. Clin Exp Nephrol.2012;16(5):697-705.

12. Hellerstein S, Berenbom M, DiMaggio S, Erwin P, et al. Comparison of two formulae for estimation of glomerular filtration rate in children. Pediatr Nephrol. 2004; 19(7):780-4.

13. De Souza VC, Rabilloud M, Cochat P, Selistre L, et al. Schwartz formula: Is one k-coefficient adequate for all children? PLoS One. 2012; 7(12):e53439.

14. Comité nacional de crecimiento y desarrollo. Guía para la evaluación del crecimiento físico. 3. ${ }^{\mathrm{a}}$ ed. Buenos Aires: Sociedad Argentina de Pediatría; 2013.

15. Remer T, Neubert A, Maser-Gluth C. Anthropometrybased reference values for 24-h urinary creatinine excretion during growth and their use in endocrine and nutritional research. Am J Clin Nutr. 2002; 75(3):561-9.

16. Du Bois D, Du Bois EF. Clinical calorimetry tenth paper a formula to estimate the appropriate surface area if height and weight be known. Arch Intern Med (Chic). 1916; 17(6_2):863-71.

17. De los Ríos Carrasco MJ, Montañés Bermúdez R, Gràcia García S. Estandarización de los procedimientos de medida de creatinina: estado actual. Rev Lab Clin. 2012; 5(2):87-101

18. Schwartz GJ, Brion LP, Spitzer A. The use of plasma creatinine concentration for estimating glomerular filtration rate in infants, children, and adolescents. Pediatr Clin North Am. 1987; 34(3):571-90.

19. Pottel H, Hoste L, Dubourg L, Eber N, et al. An estimated glomerular filtration rate equation for the full age spectrum. Nephrol Dial Transplant. 2016; 31(5):798-806.

20. Pottel H, Björk J, Bökenkamp A, Berg U, et al. Estimating glomerular filtration rate at the transition from pediatric to adult care. Kidney Int. 2019; 95(5):1234-43.

21. Mian A, Schwartz G. Measurement and Estimation of Glomerular Filtration Rate in Children. Adv Chronic Kidney Dis. 2017; 24(6):348-56. 